\title{
Development and Validation Study of the Internet Overuse Screening Questionnaire
}

\author{
Han-Kyeong Lee', Hae-Woo Lee ${ }^{2}$, Joo Hyun Han ${ }^{3}$, Subin Park ${ }^{4}$, Seok-Jin Jư \\ Kwanwoo Choi', Ji Hyeon Lee ${ }^{1}$, and Hong Jin Jeon ${ }^{1,6,7} \bowtie$ \\ ${ }^{1}$ Department of Psychiatry, Depression Center, Samsung Medical Center, Sungkyunkwan University School of Medicine, Seoul, Republic of Korea \\ ${ }^{2}$ Department of Psychiatry, Seoul Medical Center, Seoul, Republic of Korea \\ ${ }^{3}$ Department of Clinical Psychology, National Center for Mental Health, Seoul, Republic of Korea \\ ${ }^{4}$ Department of Research Planning, Mental Health Research Institute, National Center for Mental Health, Seoul, Republic of Korea \\ ${ }^{5}$ Department of Child Welfare, Kosin University, Busan, Republic of Korea \\ ${ }^{6}$ Depression Clinical and Research Program, Massachusetts General Hospital, Harvard Medical School, Boston, USA \\ ${ }^{7}$ Department of Health Sciences \& Technology, Department of Medical Device Management \& Research, and Department of Clinical Research Design \& \\ Evaluation, Samsung Advanced Institute for Health Sciences \& Technology (SAIHST), Sungkyunkwan University, Seoul, Republic of Korea
}

Objective Concerns over behavioral and emotional problems caused by excessive internet usage have been developed. This study intended to develop and a standardize questionnaire that can efficiently identify at-risk internet users through their internet usage habits.

Methods Participants $(\mathrm{n}=158)$ were recruited at six I-will-centers located in Seoul, South Korea. From the initial 36 questionnaire item pool, 28 preliminary items were selected through expert evaluation and panel discussions. The construct validity, internal consistency, and concurrent validity were examined. We also conducted Receiver Operating Curve (ROC) analysis to assess diagnostic ability of the Internet Overuse Screening-Questionnaire (IOS-Q).

Results The exploratory factor analysis yielded a five factor structure. Four factors with 17 items remained after items that had unclear factor loading were removed. The Cronbach's alpha for the IOS-Q total score was 0.91 , and test-retest reliability was 0.72 . The correlation between Young's internet addiction scale and K-scale supported concurrent validity. ROC analysis showed that the IOS-Q has superior diagnostic ability with the Area Under the Curve of 0.87 . At the cut-off point of 25.5, the sensitivity was 0.93 and specificity was 0.86 .

Conclusion Overall, this study supports the use of IOS-Q for internet addiction research and for screening high-risk individuals.

Psychiatry Investig 2018;15(4):361-369

Key Words Problematic internet use, Behavioral addiction, Screening, Scale validation, Cut-off.

\section{INTRODUCTION}

Since the beginning of the 1990s, the evolution of information technology (IT) has spawned concerns about technological addiction, ${ }^{1}$ particularly concerning internet addiction. ${ }^{2}$

\footnotetext{
Received: August 10, 2017 Revised: September 19, 2017

Accepted: September 27, 2017

$\triangle$ Correspondence: Hong Jin Jeon, MD, PhD

Department of Psychiatry, Depression Center, Samsung Medical Center, Sungkyunkwan University School of Medicine, Seoul, Republic of Korea Department of Health Sciences \& Technology, Department of Medical Device Management \& Research, and Department of Clinical Research Design \& Evaluation, Samsung Advanced Institute for Health Sciences \& Technology (SAIHST), Sungkyunkwan University, 81 Irwon-ro, Gangnam-gu, Seoul 06351, Republic of Korea

Tel: +82-2-3410-3586, Fax: +82-2-3410-0050, E-mail: jeonhj@skku.edu

(a) This is an Open Access article distributed under the terms of the Creative Commons Attribution Non-Commercial License (http://creativecommons.org/licenses/by$\mathrm{nc} / 4.0$ ) which permits unrestricted non-commercial use, distribution, and reproduction in any medium, provided the original work is properly cited.
}

However, the operational definition of internet addiction remains contentious. Whether internet addiction is even real is still debatable. While Young ${ }^{2}$ described the concept of internet addiction, Griffiths ${ }^{3}$ argued that the internet is just the place where people engage in specific behavior. That is, excessive users use the internet as a medium to fuel other addictions while not being addicted to the internet itself. ${ }^{4,5} \mathrm{~A}$ Second point of contention concerns the diagnostic criteria of internet addiction, that is what conditions should be satisfied for internet addiction diagnosis. ${ }^{6,7}$ For example, although Tao et al. ${ }^{8}$ and Griffiths ${ }^{9}$ indicated that tolerance is needed to identify addictive behavior, some researchers have argued that it is difficult to objectively define or measure tolerance for internet addiction, and there is a lack of grounds of tolerance even for substance use disorders. ${ }^{10}$ Also, it is still unclear whether internet addiction is an isolated disease entity or 
whether it is a manifestation/subset of other underlying mental disease such as depressive disorder, ${ }^{11,12}$ anxiety disorder, ${ }^{13}$ social phobia, ${ }^{14}$ attention-deficit hyperactivity disorder, ${ }^{15}$ or impulse control disorder. ${ }^{16,17}$

To clarify concepts and diagnoses of internet addiction, there have been attempts to explore the causes of the phenomenon. Some researchers argued that internet addiction can be resulted as a response or coping strategy to stressful event, ${ }^{18,19}$ since the addictive behavior tends to be triggered when one cannot achieve a sufficient satisfaction from natural rewards. ${ }^{20}$ Another study focused on individual sensation seeking tendency or impulsivity based on the unique feature of the internet that enables immediate satisfaction with minimal delay. ${ }^{19}$ Other studies suggested that demographic factors like gender, ${ }^{6}$ education, ${ }^{21}$ or socioeconomic status could be risk factors for internet addiction. ${ }^{22,23}$ Other underlying mental disorders, personality traits, or low self-esteem might also lead to internet addiction. ${ }^{24,25}$ Recent studies have suggested that similar to other substance use disorders, internet addiction is likely to be related to neurobiological abnormalities ${ }^{10}$ or dysfunctions of dopaminergic brain systems. ${ }^{26} \mathrm{How}$ ever, these studies seem to offer explanations only about vulnerabilities or the pathway to the disease state.

The reason why internet addiction studies are complicated is because internet addiction presents unique characteristics and results. For internet addiction, direct physical effects of substances do not affect the brain. However, sleep patterns are often disrupted by the extended nocturnal overuse of the internet. Snoring, teeth grinding, and sleep apnea can be prevalent in individuals considered to be internet addicts. ${ }^{27}$ This leads to fatigue during daytime, reduces academic and occupational functioning, and negatively affects physical homeostasis and immune system function. ${ }^{2,28}$ The case of a South Korean male who died due to excessive internet gaming after a few sleepless nights has caused awareness about the serious results of internet addiction. ${ }^{29}$ Also, internet addiction is likely to cause problems with family or friends, which can lead to secondary psychological and emotional problems. ${ }^{2}$

With concerns over the negative consequences of excessive internet use, many studies have tried to explore the current status of internet addiction by developing appropriate screening or diagnostic tools. However, the tools devised so far have failed to reach agreement. Criticisms of the tools include differences in the criteria between tools and lack of appropriate standardization process. ${ }^{17,30}$ Moreover, research on screening tools for at-risk internet users is insufficient with a few exceptions including the Internet Addition Test (IAT) ${ }^{2}$ or Chinese Internet Addiction Scale (CIAS). ${ }^{31}$ Even though the IAT and CIAS are widely used, these tools also have limitations. Since the IAT was intended for adults, it may not be appropriate to measure the problem of youth. The revised Korean version for adolescent was suggested, ${ }^{32}$ but the translation and modification process was not presented precisely. Also, the study did not provide diagnostic information such as cut-off point because the study was conducted with community-dwelling students without diagnostic interview. Although Young (1998) suggested cut-off point, it would be inappropriate to use it without considering the cultural differences. For CIAS, the cut-off point was well investigated. ${ }^{29}$ The study, however, did not suggest factor structure or concurrent validity of the instrument. Also, CIAS has largely been used in the Taiwan and was not standardized in Korea. Although the Korean Scale for Internet Addiction (K-scale) also has been widely used in Korea, ${ }^{33}$ it contains some ambiguous expressions that make it difficult to interpret results. For example, item 2 for adolescents (There are more people who recognize me online than offline) or adults (I become more confident during using the internet) do not seem to reflect internet addiction properly.

Since the internet is essential for academic or occupational functioning in modern society, it is difficult to determine between essential-use and overuse with only a few brief questions. In addition, the problem is easily concealed if the subject denies the symptoms. Therefore, questions that reflect various aspects of lifestyle and fulfill an unmet need of the filed are needed. Of all internet users, an estimated 3\% to 15\% might be considered addicted, with those at high-risk of becoming addicted estimated as $10 \%$ to $40 \% .{ }^{7,17,18,34}$ Internet addiction is likely to become a serious public health issue in the near future, considering that even young children use the internet these days and it can easily be accessed anytime and anywhere through smartphones. Although internet addiction was not included in the 5th edition of the Diagnostic and Statistical Manual of Mental Disorders, ${ }^{35}$ internet gaming disorder was included in the section 'condition for further study'. In this situation, a systematically developed and validated screening tool could assist in identifying current status, preventative intervention, and countermeasures.

\section{METHODS}

\section{Scale development}

A preliminary questionnaire was compiled through a comprehensive review of published research papers about internet addiction, interview material with addiction center visitors, and diagnostic criteria for both pathological gambling and substance use disorders. Next, an expert group consisting of a psychiatrist, psychologist, social worker, and sociologist determined 36 preliminary items after a series of discussions to refine the contexts. For the questions, 50 members of 
an addiction society rated the adequacy and importance of each item using a 5-point (1-5) Likert scale.

The average score rated by 50 experts was 3.94 for adequacy and 3.90 for importance. Based on the results of the assessment, an item was removed if any of the adequacy or importance scores were below 3.6 (items 7, 12, 18, 25, 28, and 33). Next, if adequacy or importance were below the mean, the expert panel discussed whether the item needed to be included in the final questionnaire considering its clinical value. Items 1 and 4 were deleted because they were similar to items 2 and 5, respectively. Items 3 and 8 were included because they were considered to have high validity for preoccupation to internet. Items $6,9,13$, and 15 were included because these were the only items representing academic neglect, tolerance, emotional relief, and attempt to conceal a problem respectively. In addition, items 27, 29, and 32 were included because these questions suggested interpersonal problems caused by excessive internet usage. Item 35 , which indicates willingness to change, was considered to have predictive value for therapeutic prognosis. Item 17 was included because it reflects evaluation from others. Finally, 28 questions were confirmed (Table 1).

\section{Participants}

The subjects were recruited through six 'I-will' centers located in Seoul, South Korea. The centers are operated for the management and intervention for internet, game, or smartphone addiction under the management of Seoul city. Most visitors are teenagers who attended at the request of family members or schools, although some visit voluntarily. The visitors of the center were given the full explanation of the study, and 158 people voluntarily signed the consent form. They included 88 men and 70 women, with an average age of 22.12 $(\mathrm{SD}=7.56)$ years. For all participants, the psychologist at each center collected information on the reason for referral or voluntary visit, and explored internet usage habits in a face-toface interview. Based on the interview material, a psychiatrist and two clinical psychologists evaluated whether a person could be classified as an problematic internet user or not, through overall assessment of internet usage time, dependence, tolerance, withdrawal symptoms, perceived controllability, subjective discomfort, and functional impairment. The Samsung Medical Center Institutional Review Board approved the study, and all participants were paid $\$ 30$ for their participation (IRB No. 2014-08-114-016).

\section{Measures}

Internet addiction screening-Questionnaire (IOS-Q)

Through the aforementioned procedure, the IOS-Q was fi- nalized. The questionnaire was designed to help clinicians to explore the internet usage habits of respondents and identify at-risk internet addiction individuals. Each respondent was asked to evaluate the frequency of the statements on a fourpoint scale (Not at all, Sometimes, Often, or Always).

\section{Young's internet addiction scale (IAT)}

To verify the concurrent validity of the SOS-Q, the IAT was used. The IAT is the most frequently used measure of internet addiction. We used a Korean translated version contained in a mental health screening survey scale book published by Seoul Child, Adolescent Mental Health Center. ${ }^{36}$ Subjects rated their internet usage habits on a 5-point Likert scale. The psychometric properties of the IAT have been verified in South Korea. ${ }^{32}$ Cronbach's alpha for this study sample was 0.95 .

\section{Korean Scale for internet addiction (K-Scale)}

We used the short-form, 15-item K-Scale for children, adolescents, and adults. ${ }^{33}$ The first K-Scale was developed by the Korea National Information Society Agency and Seoul National University in 2002 to measure internet addiction in adolescents. ${ }^{37}$ It is composed of 40 questions revised from Young's 20 item Scale. The K-Scale for adults was published in $2005 .{ }^{38}$ The measure requires individuals to rate on a 4-point scale about their internet usage habits. Based on a total score, users are classified as high-risk, potential risk, or general user groups. Cronbach's alpha coefficient was 0.78 in this study.

\section{Smartphone scale for smartphone addiction (S-Scale)}

Based on the K-Scale, the S-Scale was developed to measure smartphone addiction. The term 'internet' was changed to 'smartphones'. The S-Scale consists of 15 items, on a 4-point scale like the K-Scale. Respondents are categorized according to the total score. It has adequate reliability and validity. ${ }^{39}$ Cronbach's alpha coefficient was 0.81 in our sample.

\section{Statistical analyses}

The Statistical Package for Social Sciences version 21 (SPSS ver. 21; IBM Corp., Armonk, NY, USA) was used for analyzing group statistics, internal consistency, inter-item correlation, test-retest reliability, and concurrent validity. T-test and chisquared test were used to compare the results between addicts and non-addicts. To examine the factor structure of IOS-Q, we conducted Exploratory Factor Analysis (EFA) using Comprehensive Exploratory Factor Analysis (CEFA) Version 3.04. ${ }^{40}$ The factor analysis method used maximum likelihood extraction with oblique direct Quartimin rotation. Oblique rotation was used because correlations between factors were expected. Also, diagnostic ability of the IOS-Q was assessed by investigating sensitivity, specificity of each cut-off score using 
Table 1. Preliminary item development, and adequacy and importance rated by 50 addiction experts

\begin{tabular}{|c|c|c|c|c|c|c|c|c|c|}
\hline $\begin{array}{l}\text { Pilot } \\
\text { item }\end{array}$ & $\begin{array}{c}\text { Included } \\
\text { item }\end{array}$ & Content & $\mathrm{A}$ & I & $\begin{array}{l}\text { Pilot } \\
\text { item }\end{array}$ & $\begin{array}{c}\text { Included } \\
\text { item }\end{array}$ & Content & A & I \\
\hline 1 & & $\begin{array}{l}\text { I keep thinking about using } \\
\text { the internet. }\end{array}$ & 3.96 & 3.92 & 19 & 14 & $\begin{array}{l}\text { I skip out of school or work to go } \\
\text { somewhere I can use the internet. }\end{array}$ & 4.33 & 4.40 \\
\hline 2 & 1 & $\begin{array}{l}\text { I often think about the internet } \\
\text { even while doing other work. }\end{array}$ & 4.02 & 3.96 & 20 & 15 & $\begin{array}{l}\text { I don't think I can reduce my internet } \\
\text { usage without help from others. }\end{array}$ & 3.98 & 3.96 \\
\hline 3 & 2 & $\begin{array}{l}\text { I exceedingly wait to access the inter- } \\
\text { net again. }\end{array}$ & 3.94 & 3.85 & 21 & 16 & $\begin{array}{l}\text { Despite I am sick, I continue the internet } \\
\text { usage (e.g. lack of sleep, eye fatigue, } \\
\text { hand or neck pain, etc.) }\end{array}$ & 4.15 & 4.21 \\
\hline 4 & & $\begin{array}{l}\text { Even though it is overtime, I don't } \\
\text { sleep and keep surf the internet. }\end{array}$ & 3.88 & 3.90 & 22 & 17 & $\begin{array}{l}\text { I spend most of the allowance or salary } \\
\text { for the internet usage. }\end{array}$ & 4.02 & 3.98 \\
\hline 5 & 3 & I stay up all night using internet. & 4.23 & 4.21 & 23 & 18 & $\begin{array}{l}\text { I am late for the school, work, } \\
\text { appointment, etc. due to the } \\
\text { internet usage. }\end{array}$ & 4.46 & 4.48 \\
\hline 6 & 4 & $\begin{array}{l}\text { I am tired and sleepy during class } \\
\text { or work due to the internet usage. }\end{array}$ & 3.83 & 3.88 & 24 & 19 & $\begin{array}{l}\text { I skip meals or eat while using the } \\
\text { internet. }\end{array}$ & 4.02 & 4.00 \\
\hline 7 & & $\begin{array}{l}\text { If I have no replies, no } \\
\text { recommendations, or comments, } \\
\text { I am nervous. }\end{array}$ & 3.35 & 3.29 & 25 & & $\begin{array}{l}\text { Even if I want to go to the bathroom, } \\
\text { I keep using the internet. }\end{array}$ & 3.46 & 3.38 \\
\hline 8 & 5 & $\begin{array}{l}\text { I check the internet excessively } \\
\text { by habit. }\end{array}$ & 3.71 & 3.63 & 26 & 20 & $\begin{array}{l}\text { I use the internet instead of doing } \\
\text { things I need to do. }\end{array}$ & 4.40 & 4.33 \\
\hline 9 & 6 & $\begin{array}{l}\text { I need to use the internet for } \\
\text { a longer period of time to } \\
\text { become as satisfied as before. }\end{array}$ & 3.92 & 3.92 & 27 & 21 & $\begin{array}{l}\text { I like using the internet more than } \\
\text { socializing with friends. }\end{array}$ & 3.96 & 3.85 \\
\hline 10 & 7 & $\begin{array}{l}\text { I become irritated or angry } \\
\text { without the internet. }\end{array}$ & 4.23 & 4.23 & 28 & & $\begin{array}{l}\text { I feel that I am a better person in the } \\
\text { internet space than in real life. }\end{array}$ & 3.58 & 3.54 \\
\hline 11 & 8 & $\begin{array}{l}\text { I become anxious or nervous } \\
\text { without the internet. }\end{array}$ & 4.27 & 4.29 & 29 & 22 & $\begin{array}{l}\text { I like using the internet more than } \\
\text { spending time with family. }\end{array}$ & 3.63 & 3.52 \\
\hline 12 & & $\begin{array}{l}\text { If I can't use the internet, I feel } \\
\text { alienated from people around me. }\end{array}$ & 3.60 & 3.58 & 30 & 23 & $\begin{array}{l}\text { I quarrel with family due to the } \\
\text { internet usage. }\end{array}$ & 4.10 & 4.06 \\
\hline 13 & 9 & $\begin{array}{l}\text { When I am in bad mood, internet } \\
\text { use makes me feel better. }\end{array}$ & 3.81 & 3.83 & 31 & 24 & $\begin{array}{l}\text { I am not interested in anything except } \\
\text { the internet usage. }\end{array}$ & 3.94 & 4.00 \\
\hline 14 & 10 & $\begin{array}{l}\text { I tried to reduce the internet usage, } \\
\text { but it is difficult. }\end{array}$ & 4.33 & 4.40 & 32 & 25 & $\begin{array}{l}\text { I became distant from friends and } \\
\text { colleagues since the internet usage. }\end{array}$ & 3.65 & 3.63 \\
\hline 15 & 11 & $\begin{array}{l}\text { I underreport the amount of time } \\
\text { I spend on the internet. }\end{array}$ & 3.96 & 3.88 & 33 & & $\begin{array}{l}\text { I do internet because it is difficult to } \\
\text { hang out with friends or co-workers. }\end{array}$ & 3.40 & 3.27 \\
\hline 16 & 12 & $\begin{array}{l}\text { When I use the internet, I lose track } \\
\text { of how much time has passed. }\end{array}$ & 4.08 & 4.06 & 34 & 26 & $\begin{array}{l}\text { I think that I am addicted to the } \\
\text { internet. }\end{array}$ & 4.02 & 3.98 \\
\hline 17 & 13 & $\begin{array}{l}\text { People around me point out that } \\
\text { I spend a lot of time on the internet. }\end{array}$ & 3.92 & 3.75 & 35 & 27 & $\begin{array}{l}\text { I want to change my current internet } \\
\text { usage habits. }\end{array}$ & 3.94 & 3.88 \\
\hline 18 & & $\begin{array}{l}\text { My family keeps me from using } \\
\text { the internet. }\end{array}$ & 3.56 & 3.40 & 36 & 28 & I think I use the internet excessively. & 4.04 & 4.00 \\
\hline
\end{tabular}

A: Adequacy, I: Importance

Receiver Operating Curve (ROC) analysis. If the value of Area Under the Curve (AUC) is $<0.5$, it is considered random guess, $0.7-0.8$ is acceptable, and $\geq 0.8$ is considered excellent. ${ }^{41}$

\section{RESULTS}

\section{Demographics}

Table 2 presents the basic demographic information and internet usage habits by the addiction/non-addiction groups. 
Table 2. Descriptive statistics of basic characteristics and internet usage habits of participants

\begin{tabular}{|c|c|c|c|c|}
\hline & Addicts $(\mathrm{N}=28)$ & Non-addicts $(\mathrm{N}=130)$ & p-value & Total $(\mathrm{N}=158)$ \\
\hline Age (M, SD) & $17.61(3.81)$ & $23.10(7.82)$ & $<0.001$ & $22.12(7.56)$ \\
\hline Female, N (\%) & $18(64.29)$ & $52(40.00)$ & 0.019 & $70(44.30)$ \\
\hline \multicolumn{5}{|l|}{ Internet habits, $\mathrm{N}(\%)$} \\
\hline Average daily use time & $3.68(2.20)$ & $2.04(1.47)$ & 0.001 & $2.33(1.73)$ \\
\hline Maximum usage time per use & $5.29(4.61)$ & $3.21(3.37)$ & 0.031 & $3.58(3.69)$ \\
\hline Academic/occupational influence & $5.14(2.45)$ & $3.42(2.33)$ & 0.001 & $3.73(2.44)$ \\
\hline Household influence & $4.14(2.65)$ & $2.95(2.27)$ & 0.016 & $3.16(2.38)$ \\
\hline Interpersonal influence & $2.96(2.66)$ & $2.92(2.31)$ & 0.921 & $2.92(2.37)$ \\
\hline \multicolumn{5}{|l|}{ Main usage, N (\%) (double count) } \\
\hline Internet games & $15(19.74)$ & $36(15.25)$ & & $51(16.35)$ \\
\hline Watching broadcasting or porn & $14(18.42)$ & $40(16.95)$ & & $54(17.31)$ \\
\hline Social medias & $16(21.05)$ & $46(19.49)$ & & $62(19.87)$ \\
\hline Web surfing & $14(18.42)$ & $56(23.73)$ & & $70(22.44)$ \\
\hline Blogging or web cafes & $3(3.95)$ & $20(8.47)$ & & $23(7.37)$ \\
\hline Web-cartoon & $10(13.16)$ & $22(9.32)$ & & $32(10.26)$ \\
\hline Shopping & $4(5.26)$ & $16(6.78)$ & & $20(6.41)$ \\
\hline
\end{tabular}

Data were expressed as numbers (percent), mean \pm standard deviation. $\mathrm{p}$ value was derived from independent two sample $\mathrm{t}$-test

Differences in age, gender, and internet usage habits among addicts and non-addicts were significant. In addition, the internet addiction group highly assessed the internet's influence on academic/occupational and household function. For internet addicts, the main purpose of the internet usage was social media, internet games, web-surfing, watching broadcasting, comics, shopping, and blogging in descending order of frequency. On the other hand, the non-addiction group used internet mainly for web-surfing, social networking, watching broadcasting events, and to play internet games.

\section{Construct validity}

The significance of Bartlett's test of sphericity $\left[\chi^{2}(\mathrm{df}=378)=\right.$ 2453.23, p<0.001] and the Kaiser-Meyer-Olkin (KMO) results $(\mathrm{KMO}=0.094)$ suggested that factor analysis was appropriate for these data. The Kaiser criterion, ${ }^{42}$ scree test, ${ }^{43}$ and the root mean square of approximation (RMSEA) ${ }^{44}$ was used to determine the appropriate number of factors. The Kaiser criterion, which assesses the number of factors with eigenvalues $>1.0$, suggested 6 -factors. The drop rate of the scree plot suggested a 5- or 6-factor structure. According to these results, 4 - to 6-factor models were examined. The RMSEA of the 4-, 5-, and 6-factor model was 0.080 [ $90 \%$ confidence interval (CI): 0.070-0.089], 0.073 (90\% CI: 0.063-0.084), and 0.062 (90\% CI: 0.050-0.073), respectively, which demonstrated that the 5- or 6-factor model would be reasonable (i.e. RMSEA $<0.08) .{ }^{44}$ Although the RMSEA value of the 6 -factor model was greater, the 5 -factor structure was selected since 4 items of 6-factor structure showed under-factoring, in which the factor loading was $<0.30$.

After accepting the 5-factor solution, each item's factor loading was examined (Table 3). In order to clarify the factor structure, items that had factor loading less than 0.3 (item 3 ) and items that showed cross loading (factor loading $>0.3$ to more than 2 factors; items 2, 4, 6, 11, 12, 14, 17, 18, 24, and 26) were deleted. As a result, total of 17 items remained, and factor 3 was removed because there were no items that remained. Items that belonged to each factors are: Factor $1=$ Items 1,13 , 20, and 23, Factor 2=Items 16 and 25, Factor 4=5, 7, 8, 9, 10, 15, 27, and 28, and Factor 5=19, 21, and 22). Each factor was named loss of control, preoccupation, craving, and neglect of other areas, respectively. All the sub-factor scores were higher in the addiction group compared to the non-addiction group at the $\mathrm{p}<0.001$ level.

\section{Internal consistency and test-retest reliability}

Coefficient alphas and corrected item-total correlations were computed for the IOS-Q. The Cronbach's alpha was 0.91 for total 17 items and the corrected item-total correlations ranged from 0.34 to 0.78 . Cronbach's alpha if item deleted were 0.90 for all items. The Cronbach's alpha for sub-factors are: Loss of control $=0.79$, Preoccupation $=0.54$, Craving $=0.86$, and Neglect of other areas: 0.76 . The correlations between items of the IOS-Q ranged from 0.07 to 0.71 .

The test-retest correlation was calculated with the exception of 30 cases which missed the date of second visit. The testretest reliability for an average time lapse of 10.29 days was $0.72(\mathrm{p}<0.001)$. 


\section{Concurrent validity}

Inter-correlations between IOS-Q and other self-reported measures are presented in Table 4 . Although correlations be-

Table 3. Quartimin rotated factor loadings of preliminary 28 items

\begin{tabular}{cccccc}
\hline Item & Factor 1 & Factor 2 & Factor 3 & Factor 4 & Factor 5 \\
\hline 1 & $0.46^{*}$ & 0.15 & 0.09 & 0.23 & 0.00 \\
2 & $0.41^{*}$ & 0.02 & 0.05 & $0.46^{*}$ & -0.06 \\
3 & 0.11 & 0.06 & -0.17 & 0.00 & 0.02 \\
4 & $0.34^{*}$ & $0.48^{*}$ & -0.29 & 0.05 & 0.02 \\
5 & 0.18 & 0.13 & -0.29 & $0.35^{*}$ & -0.22 \\
6 & $0.30^{*}$ & 0.22 & -0.17 & $0.37^{*}$ & -0.09 \\
7 & -0.02 & -0.05 & 0.13 & $0.71^{*}$ & 0.06 \\
8 & 0.02 & 0.03 & 0.05 & $0.68^{*}$ & -0.09 \\
9 & -0.06 & 0.13 & 0.08 & $0.50^{*}$ & 0.10 \\
10 & -0.01 & 0.08 & -0.11 & $0.73^{*}$ & 0.15 \\
11 & $0.44^{*}$ & 0.05 & 0.09 & $0.50^{*}$ & -0.17 \\
12 & -0.10 & $0.34^{*}$ & 0.01 & $0.47^{*}$ & 0.18 \\
13 & $0.68^{*}$ & 0.01 & -0.02 & 0.03 & 0.17 \\
14 & 0.07 & 0.09 & $0.52^{*}$ & $0.40^{*}$ & -0.10 \\
15 & -0.01 & 0.09 & 0.13 & $0.52^{*}$ & 0.23 \\
16 & 0.18 & $0.36^{*}$ & -0.09 & 0.05 & 0.23 \\
17 & $0.31^{*}$ & 0.12 & $0.56^{*}$ & -0.10 & 0.22 \\
18 & $0.42^{*}$ & $0.35^{*}$ & 0.14 & 0.00 & -0.01 \\
19 & 0.19 & 0.06 & 0.02 & 0.15 & $0.38^{*}$ \\
20 & $0.30^{*}$ & 0.23 & -0.13 & 0.17 & 0.27 \\
21 & -0.02 & 0.13 & -0.03 & 0.01 & $0.79^{*}$ \\
22 & 0.05 & -0.04 & 0.11 & 0.15 & $0.74^{*}$ \\
23 & $0.61^{*}$ & 0.04 & 0.18 & 0.05 & 0.13 \\
24 & $0.40^{*}$ & -0.08 & 0.21 & 0.00 & $0.32^{*}$ \\
25 & -0.10 & $0.71^{*}$ & 0.14 & 0.02 & 0.05 \\
26 & $0.31^{*}$ & -0.18 & -0.19 & $0.44^{*}$ & $0.35^{*}$ \\
27 & -0.01 & 0.07 & -0.02 & $0.70^{*}$ & 0.09 \\
28 & 0.21 & -0.02 & -0.11 & $0.61^{*}$ & 0.18 \\
\hline
\end{tabular}

${ }^{*}$ factor loadings $>0.3$ tween all the measures were significant, the correlation between IOS-Q and the internet addiction related measures, IAT and K-Scale, were higher compared to correlations between the IOS-Q and S-Scale. Also, all the sub-factors of IOSQ showed higher correlations with IAT and K-Scale compared to S-Scale. These results support convergent and discriminant validity of the IOS-Q.

\section{ROC analysis}

Two clinical psychologists and one psychiatrist independently reviewed the interview material of all participants of I-will center and decided normal or problematic user. The diagnostic concordance rate was $94.94 \%$ among raters, and the discrepancy occurred when functional impairment, self-controllability, or excessive use was unclear. In these cases, the individual was assigned a group in which two or more experts agreed after case discussion. As a result, 28 out of 158 people were classified as internet addicts. Figure 1 shows the results

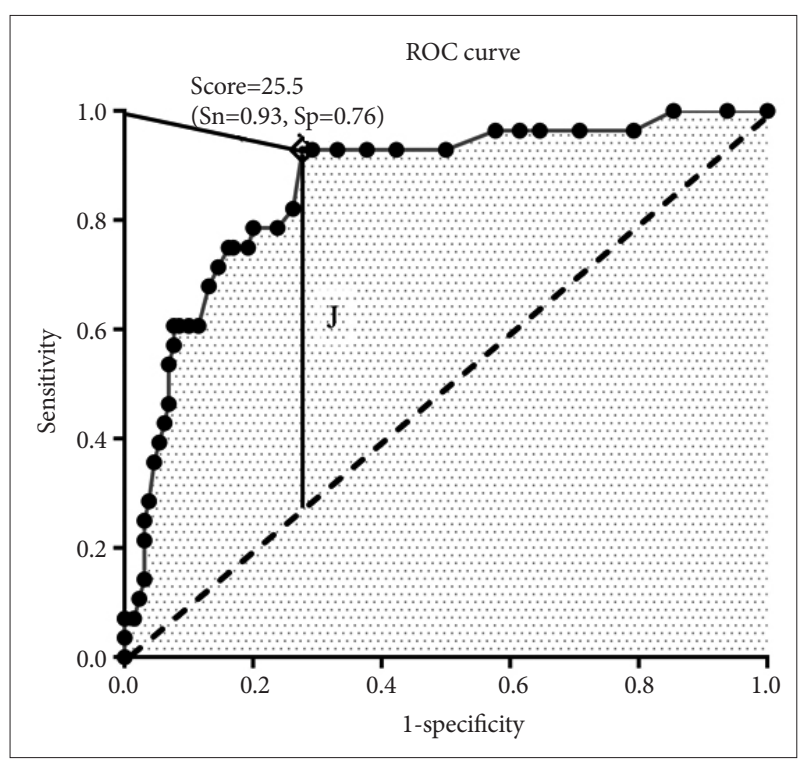

Figure 1. Receiver Operating Characteristic (ROC) Curve analysis of the 17-item IOS-Q. IOS-Q: Internet Overuse Screening Questionnaire, Sn: sensitivity, Sp: specificity, J: Youden's J Statistics.

Table 4. Correlations between other related measures and IOS-Q total and sub-factor scores

\begin{tabular}{lllllrr}
\hline \multicolumn{1}{c}{ IOS-Q } & IAT & K-scale & S-scale & M & \multicolumn{1}{c}{ SD } \\
\hline IOS-Q & 1 & & & & 25.54 & 8.03 \\
IAT & $0.745^{*}$ & 1 & & & 36.58 & 15.94 \\
K-Scale & $0.551^{*}$ & $0.562^{*}$ & 1 & & 28.99 & 6.56 \\
S-Scale & $0.504^{*}$ & $0.513^{*}$ & $0.522^{*}$ & 1 & 29.57 & 6.84 \\
Loss of control & $0.862^{*}$ & $0.642^{*}$ & $0.411^{*}$ & $0.360^{*}$ & 6.20 & 2.40 \\
Preoccupation & $0.591^{*}$ & $0.460^{*}$ & $0.320^{*}$ & $0.273^{*}$ & 2.54 & 0.83 \\
Craving & $0.792^{*}$ & $0.516^{*}$ & $0.489^{*}$ & $0.487^{*}$ & 6.47 & 2.16 \\
Neglect of other areas & $0.750^{*}$ & $0.644^{*}$ & $0.404^{*}$ & $0.324^{*}$ & 4.06 & 1.60 \\
\hline
\end{tabular}

*all correlations were $\mathrm{p}<0.001$. IOS-Q: Internet Overuse Screening-Questionnaire, IAT: Young Internet Addiction Test 
Table 5. Results of Receiver Operating Curve Analysis of IOS-Q

\begin{tabular}{|c|c|c|c|c|c|c|}
\hline & \multicolumn{2}{|c|}{$\mathrm{M}(\mathrm{SD})$} & \multirow{2}{*}{ AUC } & \multirow{2}{*}{$\begin{array}{l}\text { Cut-off } \\
\text { score }\end{array}$} & \multirow{2}{*}{ Sensitivity } & \multirow{2}{*}{ Specificity } \\
\hline & Addiction $(\mathrm{N}=28)$ & Non-addiction $(\mathrm{N}=130)$ & & & & \\
\hline IOS-Q total score & $34.21(8.57)$ & $23.33(6.24)$ & 0.87 & 25.5 & 0.93 & 0.76 \\
\hline Loss of control & $7.38(2.88)$ & $5.63(1.90)$ & 0.81 & 6.5 & 0.79 & 0.78 \\
\hline Preoccupation & $3.17(1.20)$ & $2.39(0.63)$ & 0.67 & 2.5 & 0.61 & 0.65 \\
\hline Craving & $7.76(2.29)$ & $6.13(2.00)$ & 0.78 & 6.5 & 0.71 & 0.71 \\
\hline Neglect of other areas & $5.79(2.34)$ & $3.63(1.01)$ & 0.77 & 4.5 & 0.70 & 0.80 \\
\hline
\end{tabular}

IOS-Q: Internet Overuse Screening-Questionnaire, AUC: Area Under the Curve

of the ROC analysis of the final 17 items. The AUC value was 0.87 (95\% CI: 0.80-0.95), and the optimal cut-off score was 25.5 considering the sensitivity and the specificity determined by Youden's J statistic. The point determined by the Youden's index represents the furthest point from the diagonal line, where the sum of the sensitivity and specificity can be maximized. ${ }^{45}$ At the cut-off point of 25.5, the sensitivity and the specificity was 0.93 and 0.76 , respectively. Results of ROC analysis of sub-factors are presented in Table 5.

\section{DISCUSSION}

This study identified the developmental process of the IOS$\mathrm{Q}$ and explored the psychological properties of the scale. Internal reliability was superior, except for one sub-factor (preoccupation). Inter-item correlation and test-retest reliability were adequate. Moreover, the correlations between the IOS-Q and the internet-related measures supported concurrent validity of the scale. EFA revealed a 5-factor structure, with all sub-factor scores being higher in the addiction group compared to the non-addiction group, supporting content validity. ROC analysis revealed that addiction and non-addiction group can be effectively distinguished based on a cut-off score of 25.5. Regarding the result of ROC analysis, it should be noted that the cut-off score and the total mean score were almost similar. Given that it is usually considered abnormal from 1.5 standard deviation above the mean based on normal distribution, it is likely that the cut-off score of this study was somewhat lower. This could be due the under-reporting of problems by the affected individuals. Since internet addicts often underreport their symptoms, this cut-off score is plausible for screening purposes, assuring adequate sensitivity of the instrument.

The average daily internet usage time was $<4$ hours even in those classified as internet addicted. Considering that initial study of internet addiction defined internet addiction as 'use of internet more than 38 hours per week, ${ }^{19}$ this seems less than expected. Similar results have been reported in several previous studies. For example, in a review study by Dowling and Quirk, ${ }^{46}$ there were no significant differences in internet usage time and psychological distress between internet addicts and non-addicts. The authors discussed the possibility of limited internet use due to management of parents or schools. Although the influence of the internet to academic/ occupational and household function was highly estimated by internet addiction group compared to non-addiction group in our sample, it was normal range on a Likert scale of 1 to 10 . Internet over-users might have thought that there is no problem with that amount of usage time. Also, there were cases in the sample complaining of craving symptoms even though actual usage time was average, or who cannot remember their own usage time exactly. Given this, the intent of the IOS-Q to identify problematic internet users through various internet usage habits seems reasonable.

There are several limitations in this study. Although environmental factors such as social economic status might be related to internet addiction, ${ }^{18,21}$ we could not examine these variables since most of our samples were single students. In addition, the question whether internet addiction is an isolated disease entity or related to other comorbid mental disorders cannot be answered because we did not carry out a structured clinical interview. There are other limitations related to methodological issues. First of all, it is likely that the respondents were disingenuous or insincere because all the measures were self-report. Also, due to the fact that the participants were recruited through the I-will center, there is a possibility that the sample have been biased. Finally, given the number of items included in the factor analysis $(n=28)$, a sample of 158 participants might not be able to provide sufficient power to support the analysis. The 5-factor structure revealed in this study should be re-examined with confirmatory factor analysis in the future study.

Despite these limitations, the IOS-Q underwent a systematical development and standardization process: i.e. item rating by 50 addiction experts, and group classification and case discussion by independent clinicians. The overall psychological properties of the questionnaire turned out to be favorable. Research on internet addiction is still in development, and this instrument would be worthwhile to identify the status and characteristics of the phenomenon. However, in the ab- 
sence of consensus on the definition of internet addiction, it should be noted that we cannot solely rely on this instrument for screening or diagnosis purposes. The IOS-Q should serve as the basis for in-depth discussions.

\section{Acknowledgments}

This study was supported by a grant of the Korean Mental Health Technology R\&D Project, Ministry of Health \& Welfare, Republic of Korea (No. HM14C2567; PI, HJJ). This work was partly supported by Institute for Information \& communications Technology Promotion (IITP) grant funded by the Korea government (MSIP) (No. B0132-15-1003, the development of skin adhesive patches for the monitoring and prediction of mental disorders), and by the Original Technology Research Program for Brain Science through the National Research Foundation of Korea (NRF) funded by the Ministry of Education, Science and Technology (No. NRF2016M3C7A1947307; PI HJJ), and the Bio \& Medical Technology Development Program of the NRF funded by the Korean government, MSIP (No. NRF-2017M3A9F1027323; PI HJJ).

\section{REFERENCES}

1. Griffiths M. Behavioral addiction: an issue for everybody? J Workplace Learn 1996;8:19-25.

2. Young KS. Internet addiction: the emergence of a new clinical disorder. Cyberpsychol Behav 1998;1:237-244.

3. Griffiths M. Internet addiction-time to be taken seriously? Addict Res 2000;8:413-418.

4. Widyanto L, Griffiths M. 'Internet addiction': a critical review. Int J Ment Health Addict 2006;4:31-51.

5. Griffiths M. Internet addiction: Internet fuels other addictions. Student BMJ 1999;7:428-429.

6. Chou C, Condron L, Belland JC. A review of the research on Internet addiction. Educ Psychol Rev 2005;17:363-388.

7. Fu KW, Chan WS, Wong PW, Yip PS. Internet addiction: prevalence, discriminant validity and correlates among adolescents in Hong Kong. Br J Psychiatry 2010;196:486-492.

8. Tao R, Huang X, Wang J, Zhang H, Zhang Y, Li M. Proposed diagnostic criteria for internet addiction. Addiction 2010;105:556-564.

9. Griffiths M. A 'components' model of addiction within a biopsychosocial framework. J Subst Use 2005;10:191-197.

10. Van Rooij A, Prause N. A critical review of "Internet addiction" criteria with suggestions for the future. J Behav Addict 2014;3:203-213.

11. Ko CH, Yen JY, Chen CS, Yeh YC, Yen CF. Predictive values of psychiatric symptoms for internet addiction in adolescents: a 2-year prospective study. Arch Pediatr Adolesc Med 2009;163:937-943.

12. Ko CH, Yen JY, Chen CS, Chen CC, Yen CF. Psychiatric comorbidity of internet addiction in college students: an interview study. CNS Spectr 2008;13:147-153.

13. Black DW, Belsare G, Schlosser S. Clinical features, psychiatric comorbidity, and health-related quality of life in persons reporting compulsive computer use behavior. J Clin Psychiatry 1999;60:839-844.

14. Caplan SE. Relations among loneliness, social anxiety, and problematic Internet use. Cyberpsychol Behav 2006;10:234-242.

15. Young J. Common comorbidities seen in adolescents with attentiondeficit/hyperactivity disorder. Adolsce Med State Art Rev 2008;19:216228, vii.

16. Cao F, Su L, Liu T, Gao X. The relationship between impulsivity and Internet addiction in a sample of Chinese adolescents. Eur Psychiatry 2007;22:466-471.

17. Kaltiala-Heino R, Lintonen T, Rimpelä A. Internet addiction? Potentially problematic use of the Internet in a population of 12-18 year-old adolescents. Addict Res Theory 2004;12:89-96.

18. Weinstein A, Lejoyeux M. Internet addiction or excessive internet use.
Am J Drug Alcohol Abuse 2010;36:277-283.

19. Murali V, George S. Lost online: an overview of internet addiction. Adv Psychiatr Treat 2007;13:24-30.

20. Fanning P, O’Neill JT. The Addiction Workbook: A Step-by-Step Guide to Quitting Alcohol \& Drugs. Oakland, CA: New Harbinger Publications; 1996.

21. Shotton MA. The costs and benefits of 'computer addiction'. Behav Inf Technol 1991;10:219-230.

22. Park SK, Kim JY, Cho CB. Prevalence of Internet addiction and correlations with family factors among South Korean adolescents. Adolescence 2008;43:895-909.

23. Tsitsika A, Critselis E, Kormas G, Filippopoulou A, Tounissidou D, Freskou A, et al. Internet use and misuse: a multivariate regression analysis of the predictive factors of internet use among Greek adolescents. Eur J Pediatr 2009;168:655-665.

24. Armstrong L, Phillips JG, Saling LL. Potential determinants of heavier Internet usage. Int J Hum Comput Stud 2000;53:537-550.

25. Ko CH, Yen JY, Yen CF, Lin HC, Yang MJ. Factors predictive for incidence and remission of internet addiction in young adolescents: a prospective study. CyberPsychol Behav 2007;10:545-551.

26. Hou H, Jia S, Hu S, Fan R, Sun W, Sun T, et al. Reduced striatal dopamine transporters in people with internet addiction disorder. J Biomed Biotechnol 2012;2012:854524.

27. Choi K, Son H, Park M, Han J, Kim K, Lee B, et al. Internet overuse and excessive daytime sleepiness in adolescents. Psychiatry Clin Neurosci 2009;63:455-462.

28. Scherer K. College life on-line: healthy and unhealthy Internet use. J Coll Stud Dev 1997;38:655-665.

29. Ko CH, Yen CF, Yen CN, Yen JY, Chen CC, Chen SH. Screening for internet addiction: an empirical study on cut-off points for the Chen Internet Addiction Scale. Kaohsiung J Med Sci 2005;21:545-551.

30. Beard KW. Internet addiction: a review of current assessment techniques and potential assessment questions. CyberPsychol Behav 2005;8:7-14.

31. Chen S, Weng L, Su Y, Wu H, Yang P. Development of a Chinese Internet addiction scale and its psychometric study. Chin J Psychol 2003; 45:279-294.

32. Kim EJ, Lee SY, Oh SG. The Validation of Korean Adolescent Internet Addiction Scale (K-AIAS). Korean J Clin Psychol 2003;22:125-139.

33. Sin G, Kim D, Jeung Y. Third Standardization of Korean Internet Addiction Proneness Scale. Seoul: National Information Society Agency; 2011.

34. Block JJ. Issues for DSM-V: Internet addiction. Am J Psychiatry 2008; 165:306-307.

35. American Psychiatric Association. Diagnostic and Statistical Manual of Mental Disorders: DSM-5 (5th Ed.) Washington, DC: American Psychiatric Association; 2013.

36. Seoul Mental Health Center. Mental Health Screening Test Scale Book for Child and Adolescent Community Center. Seoul: Seoul Child \& Adolescent Mental Health Center; 2007.

37. Kim C, Kim D, Park J, Lee S. A study on internet addiction counseling and the development of prevention programs. Seoul: National IT Industrial Promotion Agency; 2002.

38. Lee S, Lee H, Choi Y, Choi S. A study of Internet Addiction Proneness Scale for Adults. Seoul: Addiction Prevention Team, Reverse Function Prevention Center, Korea Agency for Digital opportunity and Promotion; 2005.

39. Shin K, Kim D, Jung Y. Development of Korean Smart Phone Addiction Proneness Scale for Youth and Adults. Seoul: Korean National Information Society Agency; 2011.

40. Browne M, Cudeck R, Tateneni K, Mels G. CEFA: Comprehensive Exploratory Factor Analysis, Version 3.04 [Computer software and manual]. 2010.

41. Hanley JA, McNeil BJ. The meaning and use of the area under a receiver operating characteristic (ROC) curve. Radiology 1982;143:29-36. 
42. Kaiser HF. A second generation little jiffy. Psychometrika 1970;35:401415.

43. Zwick WR, Velicer WF. Factors influencing four rules for determining the number of components to retain. Multivariate Behav Res 1982;17: 253-269.

44. Browne MW, Cudeck R. Alternative ways of assessing model fit. Sociol
Methods Res 1992;21:230-258.

45. Kumar R, Indrayan A. Receiver operating characteristic (ROC) curve for medical researchers. Indian Pediatr 2011;48:277-287.

46. Dowling NA, Quirk KL. Screening for internet dependence: do the proposed diagnostic criteria differentiate normal from dependent internet use? CyberPsychol Behav 2009;12:21-27. 